\title{
LAS CIUDADES DE WALTER BENJAMIN. UNA APROXIMACIÓN AL CONCEPTO BENJAMINEANO DE CIUDAD MODERNA
}

Nelson Zúñiga González

\section{RESUMEN}

El presente ensayo indaga en el concepto de "ciudad moderna" que se desprende de la lectura de una serie de textos del filósofo alemán Walter Benjamin. En estos textos, el autor no intenta una definición del concepto de ciudad ni tampoco ingresa en una discusión urbanistica. Sin emabargo, es posible observar cierta perspectiva, una forma benjamineana de tratar del tema de la ciudad, que se relaciona al mismo tiempo con las acciones de recordar y escribir. Es decir, el método con el que Benjamin se aproxima a los fenómenos urbanos modernos está completamente mediado por la subjetividad y por lenguaje escrito. En este sentido, su evocación de las ciudades de Berlín y París resultan paradigmáticas y nos permiten inferir la noción de ciudad moderna sobre la que Benjamin articula los textos analizados en esta investigación. Finalmente, este ensayo propone que tanto el método benjamineano como su concepción de la ciudad moderna está relacionada con la fragmentariedad urbana producto del capitalismo industrial, lo que incidiría en su percepción de la urbe moderna como un espacio de disgregación del sentido.

Palabras-clave: Ciudad. Modernidad. Fragmentariedad. Disgregación. Sentido

\section{THE CITIES OF WALTER BENJAMIN. AN APPROXIMATION TO THE BENJAMINEAN CONCEPT OF MODERN CITY}

\begin{abstract}
This essay addresses the concept of "modern city" that can be deduced by reading a series of texts by German philosopher Walter Benjamin. In these texts, the author does not attempt a definition of the concept of city, nor concerns himself with an urbanistic discussion. However, it is possible to observe a certain perspective, a benajminean way to face the topic of the city, that is also related to the actions of remembering and writing. That is, the method that Benjamin uses to approach the modern urban phenomena is completely mediated by subjectivity and the written language. In that way, his evocation of the cities of Berlin and Paris comes to be paradigmatic and allows us to deduce the notion of modern city upon which Benjamin articulates the texts analyzed in this research. Finally, this essay proposes that the benjaminean method, as well as his conception of the modern city, is related to the urban fragmentary nature that is the product of industrial capitalism, which could influence his perception of the modern city as a place of disintegration of sense.
\end{abstract}

Key-words: City. Modernity. Fragmentary. Disintegration. Sense. 
Abordar el concepto de ciudad que subyace a los escritos de Walter Benjamin puede resultar una tarea ardua y de compleja realización. Sin ir más lejos, se corre el mismo riesgo que asumió el filósofo al emprender su Libro de los pasajes, esto es, que el trabajo quede inconcluso. Sin embargo, y a la luz de la forma en que Benjamin se plantea no solo la reflexión filosófica sino también la escritura, se podría concebir la incompletitud ya no como un perjuicio, sino como un método de trabajo, un verdadero proceder que une y relaciona fragmentos; la búsqueda de una sintaxis material que logre extraer un significado a los objetos encontrados.

¿Qué es, en términos de Walter Benjamin, la ciudad moderna? ¿Qué características tiene?, ¿Cuáles son las tensiones que la configuran y le otorgan su fisonomía material y humana? ¿Es la ciudad moderna solo una escenificación de los poderes que la rigen o, por el contrario, se trata del escenario de una lucha permanente por instalar significados diversos? Estas son algunas de las preguntas que me han guiado en la realización de este ensayo. No podría asegurar que una vez concluida la lectura del mismo estas preguntas encuentren una respuesta, pero tampoco he buscado ningún tipo de clausura. Por el contrario, si estas preguntas adquieren algún matiz diferente o ayudan a iluminar en alguna medida las lecturas bejamineanas o a abordarlas con una pequeña pero nueva motivación, estas preguntas habrán cumplido con su labor.

En términos generales, tiendo a pensar que Walter Benjamin propone a la ciudad moderna como un espacio de disgregación del sentido, es decir, como una escenificación discontinua de la vida de los sujetos que la habitan. Esto se vería reflejado en la forma misma de tratar textualmente la ciudad, de forma evocativa y fragmentaria, pero también concretamente, a través de ciertos personajes que representan justamente la contracara del poder oficial, como ocurre con los traperos, el flâneur, los conspiradores y el poeta. 
Benjamin toca los temas relativos a las ciudades de forma fragmentaria y desde casos particulares de personajes, lugares o situaciones. Este modo de acercarse al tema sería mucho más que una "marca de estilo", sino que se trataría de un rasgo metodológico, como también de una cierta dirección estética de la forma en que Benjamin habría comprendido la ciudad. Dicho de otro modo, la diseminación de los enunciados relativos al concepto de ciudad en Benjamin serían muestra de una forma de pensar la ciudad moderna como un espacio tensionado por fuerzas opuestas, polaridades que se reflejarían en el modo de vida del ciudadano moderno.

En este ensayo me he propuesto indagar en el concepto de "ciudad moderna" que subyace en los textos de Walter Benjamin referidos directa o indirectamente a París y a Berlín, contrastar los distintos fragmentos, identificar las polaridades que tensionarían la ciudad moderna en los textos analizados y, sobre todo, proponer una lectura que relacione el imaginario benjamineano de la ciudad moderna con su particular forma de abordar el tema. El texto se halla dividido en tres momentos: en la primera parte, titulada La ciudad, se emprende una discusión teórica preliminar desde ámbitos estrictamente urbanísticos, con el objetivo de extraer algunos conceptos ineludibles a la hora de reflexionar respecto de la ciudad como fenómeno cultural complejo, con la intención de que estos conceptos sean funcionales a mi lectura de los textos de Benjamin. En la segunda parte, titulada Las ciudades de Walter Benjamin, paso directamente a rastrear el concepto de ciudad moderna en los textos del autor, contrastando sus proposiciones con los conceptos extraídos de la primera parte, cuando ha sido pertinente. En la tercera parte y final, titulada Perspectivas, y que hace las veces de conclusiones provisionales- a este ensayo, he tratado de llevar la discusión hacia una lectura propositiva de los conceptos benjamineanos relativos a la urbe moderna, a la vez que realizar una proyección sobre las ciudades contemporáneas. 


\section{La ciudad}

En primer lugar, para realizar un abordaje teórico del concepto de ciudad moderna y dar cuenta de las relaciones que este establece con otros ámbitos del quehacer humano, resulta necesario aproximarse, aunque sea de manera provisoria y tentativa, al concepto de ciudad. Para este fin hemos recurrido al ámbito del urbanismo, específicamente a dos autores que han escrito sobre la ciudad como hecho material e histórico: Gustavo Munizaga y Charles Delfante. El primero de ellos, en su obra Las ciudades y su historia: una aproximación, reconoce tres factores determinantes no solo en el surgimiento de la ciudad, sino en su desarrollo permanente: "La ciudad es un invento más y un resumen tecnológico de esta capacidad inventiva [del ser humano]. El hombre hace su paisaje cultural, lo fabrica y cambia la naturaleza y la humaniza. La ciudad es artefacto de la historia" (MUNIZAGA, 1997, 23-4).

De esta perspectiva de la ciudad, me interesa principalmente el hecho de que, para el autor, la ciudad es un artefacto de la historia, es decir, es un asentamiento humano permanente a la vez que un gran objeto, casi podría decirse un mecanismo, cuyo devenir resulta marcado al mismo tiempo por una permanencia espacial y por el cambio más o menos constante. Esta perspectiva nos permite visualizar a la ciudad como un escenario social y material pleno de interacciones, siendo a la vez el contexto concreto de dichas interacciones y producto de las mismas. También, como señala Munizaga, la ciudad es un invento más, destacando con esto su carácter de evento material que responde a un conjunto de necesidades, lo que implica que las materialidades de la ciudad no son nunca políticamente neutras. Para el autor, la ciudad es "un modo permanente de vida colectiva" (Ibíd.), sujeto a las injerencias de diversas ideologías.

Para complementar la discusión respecto a cómo comprender la noción de ciudad, me ha parecido pertinente realizar un contraste con los planteamientos del 
urbanista francés Charles Delfante, responsable de la reestruturación del centro de la ciudad de Lyon en 1961. Su extensa Gran historia de la ciudad comienza planteando una visión desencantada sobre la urbe contemporánea:

Me temo que es totalmente inútil recordar que nuestras ciudades, que fueron despojadas de su alma y de su espíritu a medida que fue desapareciendo en ellas el sentimiento de comunidad, han dejado de serlo, para convertirse tan solo en meras aglomeraciones. Sin límites, a falta de cualquier idea directriz, ya no son más que el rostro de las sociedades que las han producido. Por lo demás, ya no están al servicio de las poblaciones que las convirtieron en elementos clave del desarrollo y del progreso: son solo acumulaciones de penalidades, de trampas, de peligros y de amenazas que afectan a la salud y a la moral de los que en otro tiempo eran llamados "ciudadanos" (DELFANTE, 2006, 7).

Sin embargo, por muy extensa que sea, toda teorización sobre la ciudad corre el riesgo de reducir sus características, restringir sus significados e incluso hacer abstracción de su materialidad funcional como lugar de habitación. Como propone Delfante: "Desde hace milenios [las ciudades] han sido la expresión de un deseo expresado a través de trazados matemáticos, geométricos, filosóficos, ideológicos, simbólicos [...] sin que nadie haya podido jamás reducirlas a una utopía simplificadora, porque son el reflejo de la complejidad de la vida cotidiana" (DELFANTE, 2006, 11).

Para el autor es fundamental la relación y diferencia que existe entre el planeamiento de la ciudad en cuanto trazado y su concreción en una determinada composición urbana. Por tanto, su forma de observar el fenómeno urbano está directamente relacionada con conceptos como el ejercicio del poder:

es obligado constatar que los poderes políticos, religiosos o militares dan nacimiento a dos principios fundamentales en materia de urbanismo: el ORDEN, que parece necesario porque permite atribuir papeles en una jerarquía de relaciones de dependencia, de complementariedad o de otra índole; y el SIMBOLISMO, que permite poner de relieve la grandeza y la verdad del poder instaurado. Estos dos principios generan una voluntad de puesta en escena 
indispensable para la mediatización inmediata y portadora de la gloria anunciada (DELFANTE, 2006, 11-2).

Es decir, Delfante identifica aquí un hecho fundamental: la ciudad es tanto el escenario como el espectáculo del poder que ejercen quienes la dominan o intentan dominar. Por lo tanto, es también manifestación material de la violencia y de las diversas disputas por hacerse con ese poder. Otro punto importante es el hecho de que Delfante asocia al orden (manifestación de un poder normativo) la idea de simbolismo. Esta afirmación del carácter simbólico de los espacios urbanos vincula sus planteamientos con la estética-política, por ejemplo, pero también con el ámbito de los imaginarios urbanos, en cuanto concibe a la ciudad al mismo tiempo como concreción y símbolo, es decir, como materialidad y como la percepción culturalmente significativa de esa materialidad.

En esta misma línea, el urbanista dedica una parte de la introducción de Gran historia de la ciudad a una exposición de su pensamiento sobre la estética urbana. El autor asocia el concepto de estética tanto a la noción de belleza como a las arquitectónicas y urbanísticas, centrándose en este último caso en la percepción del espacio: "El éxito del espacio urbano nace de la salvaguardia de la sociabilidad [...] la cohesión espacial se revela un elemento clave. La estética urbana es más que un concepto de coherencia armónica o audaz que genera las formas materiales de la ciudad, es una armadura compleja que preserva las relaciones entre los hombres" (DELFANTE, 2006, 16). Delfante expone aquí un elemento fundamental: la relación de las formas materiales de la ciudad con las percepciones de los individuos o grupos de individuos en una experiencia estética de la misma. Delfante utiliza las nociones de coherencia y cohesión, conceptos que además son las características fundamentales de todo texto. De esta forma, la ciudad en cuanto tejido urbano, y la literatura -o los textos en general- en cuanto tejido lingüístico, compartirían estos principios fundamentales que posibilitan su percepción y su comprensión por parte de los individuos. 
Otro texto ineludible para el estudio de la ciudad moderna es Carne y piedra. El cuerpo y la ciudad en la civilización occidental, de Richard Sennett. En el capítulo titulado "Cuerpos en movimiento. La revolución de Harvey", Sennett se remonta al siglo XVII para indagar en los orígenes del concepto de circulación en el ámbito de las ciencias médicas, concepto que más tarde se aplicará a la economía con Adam Smith y al urbanismo por parte de los planificadores urbanos de la llustración. Este concepto, sus desplazamientos y aplicaciones resulta fundamental para la propuesta de Sennett, ya que el autor lo vincula con un hecho histórico determinante para el desarrollo de la ciudad occidental, el surgimiento del capitalismo moderno: "Las nuevas ideas sobre el cuerpo coincidieron con el nacimiento del capitalismo moderno y contribuyeron a la gran transformación social que denominamos 'individualismo'. El individuo moderno es, por encima de todo, un ser humano móvil" (SENNETT, 1997, 273-4). De esta forma, Sennett apunta al desarrollo urbano como un lugar de experimentación y plasmación material de ciertas ideologías. En este caso, el capitalismo adopta el concepto de circulación como un principio fundamental aplicable a casi todas las esferas de la vida: desde el mercado con la circulación de bienes y capital financiero hasta la ciudad, con la circulación de los cuerpos.

Para Sennett, este afán por la libre circulación individual produjo una progresiva atomización social, una falta de identificación con la comunidad, lo que redunda en el aislamiento del individuo y la falta de confianza que caracteriza a la ciudad moderna: "el movimiento ha contribuido a privar al cuerpo de sensibilidad. Este principio general se ha hecho realidad en las ciudades sometidas a las necesidades del tráfico y del movimiento individual rápido, ciudades llenas de espacios neutrales, ciudades que han sucumbido al valor dominante de la circulación" (SENNETT, 1997, 274). De esta forma Sennett no solo le otorga validez al concepto que indaga, sino que además lo sitúa en una perspectiva histórica.

En el capítulo "Individualismo urbano", el autor expone justamente el surgimiento de esta conducta, conceptualizándola a partir del desarrollo de las Doctor () en Literatura con mención en literatura chilena e hispanoamericana por la Universidad de Chile. Chileno, residente en Santiago. Email: ndzuniga77@gmail.com 
ciudades de Londres y París. Las propuestas expresadas por Sennett nos resultan pertinentes por varios motivos. El primero es que el concepto de individualismo está asociado a la urbe moderna, derivado de lo expuesto previamente con respecto a la idea de circulación y sus alcances tanto económicos como urbanísticos. El segundo motivo es que Sennett enfoca su atención en Londres y París, ciudades que suscitan el interés de Benjamin, sobre todo esta última. Un tercer motivo resulta de algunos de los ejemplos del autor con respecto al diseño del espacio urbano en torno a la circulación individual y cómo esta habría determinado la forma en que la ciudad es experimentada y percibida por los individuos: "La planificación urbana del siglo XIX intentó crear una masa de individuos que se desplazaran con libertad y dificultar el movimiento de los grupos organizados por la ciudad" (SENNETT, 1997, 344).

Con respecto a la planificación del espacio urbano especialmente diseñado para la circulación, Sennett apunta que: "La relación entre la forma edificada y el cuerpo en movimiento era importante y el avance de los vehículos o los individuos estaba marcado por monumentos, iglesias u otras estructuras" (SENNETT, 1997, 353). Se puede apreciar aquí una idea coincidente con lo expuesto por Delfante respecto de la ciudad como escenificación estética de un cierto poder, al mismo tiempo que es posible extraer de estos planteamientos un punto en que apoyar una lectura de la ciudad: la planificación urbana, en tanto concreción estética de un poder, se constituye como un relato de ese poder. Este relato está marcado, como plantea Sennett, por la circulación. Sin embargo, ese relato generado desde los centros de poder que gobiernan la materialidad urbana propone una cierta direccionalidad, la que puede ser cuestionada, contravenida y/o subvertida por los individuos en un desplazamiento realizado a contrapelo de la circulación impuesta. Parafraseando a Raymond Williams, recordemos que la hegemonía nunca es un estado fijo, unívoco y unidireccional de ejecución del poder, sino que se trata de un proceso móvil en que interactúan fuerzas de diversa índole, que van moldeando el escenario social (WILLIAMS, 2000, 131-4). 
Los trabajos de los autores hasta aquí mencionados me proveen de una base general para aproximarme al complejo y siempre móvil objetivo de comprender el concepto de ciudad. Pienso (con algunos de los autores aquí expuestos) que toda definición que se pretenda total sobre el concepto de ciudad, quedará siempre rezagada con respecto a la realidad que intenta atrapar. $\mathrm{He}$ preferido, en lugar de ofrecer una definición -que me parecería estática o reduccionista-, exponer las distintas propuestas de acercamiento al concepto de ciudad y extraer de ellas los conceptos más relevantes para el análisis y la discusión.

\section{Las ciudades de Walter Benjamin}

La ciudad moderna es un tejido fragmentario. Su misma configuración se resiste a las planificaciones y modificaciones urbanas que intentan imponerse sobre ella. Porque la ciudad moderna no es solo una acumulación de calles y edificios, o la alternancia de espacios públicos y privados. La ciudad es, ante todo, la forma de habitar que sus ciudadanos practican. Las prácticas del habitar configuran la ciudad tanto como esta determina a sus habitantes. En los escritos de Walter Benjamin, las ciudades modernas aparecen desde distintos puntos de vista, de acuerdo a los temas y objetos que el filósofo intenta hilar y relacionar con el entorno urbano. Ya sea que se trate de la poesía de Baudelaire, los panoramas, los pasajes parisinos o los recuerdos de su infancia en Berlín, la ciudad moderna, al mismo tiempo que emerge en sus ensayos, parece volverse un espacio elusivo, borroso, cuya mediatización por medio de las palabras se oscureciera más que se acercara a una conceptualización precisa.

Si bien es cierto que Benjamin escribe sobre la ciudad -especialmente París-, su interés parece estar en ciertos fragmentos, lugares o personajes que le intrigan y que le suscitan una reflexión que va más allá del lugar o personaje en cuestión. De cierto modo, los fenómenos urbanos modernos parecen ser para Benjamin un punto de partida, el foco de una perspectiva cuyo seguimiento se 
develará problemático, señalará una fisura o una fricción con respecto al contexto cultural en el que están insertos. En ese sentido, podemos imaginar a Benjamin como un verdadero arqueólogo de la modernidad, desenterrando de los estratos urbanos los vestigios o, en sus propias palabras, las huellas dispersas de una cultura. Sin embargo, las huellas y fragmentos que Benjamin observa no parecen referirse a sí mismas. Es decir, hablan de sí en cuanto materialidad, pero a la luz de los escritos benjamineanos es posible observar un intento de disponer los fragmentos urbanos en una especie de polifonía, por lo demás discordante, donde no parece existir coherencia entre los distintos fragmentos, o bien esta es producto de una cierta perspectiva, más que una característica inherente a dichos fragmentos.

En ese mismo sentido, es notorio que Benjamin no está interesado en los relatos monolíticos u "oficiales" respecto de las ciudades. Muy por el contrario, deja entrever su sospecha respecto de los discursos monumentales, que inciden en los tejidos urbanos creando hitos que celebran el poder al mismo tiempo que lo ejercen. La sospecha de Benjamin recae por ejemplo sobre la remodelación de París por parte del Barón Haussmann con una distancia crítica similar con la que recuerda la Columna Triunfal en Berlín. En cuanto sujeto moderno, Benjamin está más interesado, por decirlo así, en lo que queda a la sombra de los monumentos oficiales. Su mirada se dirige a los espacios residuales de las grandes ciudades, a los intersticios que las clases sociales generan entre sí en un capitalismo industrial que vuelve inestables las categorías del pasado. De este modo es posible comprender su interés, a partir de Baudelaire, por las figuras del trapero, los conspiradores profesionales o el flâneur, todos los cuales son, cada uno a su particular modo, marginales en una sociedad que devela, para Benjamin, una crisis que se va haciendo permanente.

Benjamin piensa la ciudad moderna principalmente desde dos puntos de partida: la escritura y el recuerdo. En cuanto a la escritura, recurre por supuesto a Baudelaire, pero también a Victor Hugo, Marx y Engels, entre otros. El recuerdo, Doctor (c) en Literatura con mención en literatura chilena e hispanoamericana por la Universidad de Chile. Chileno, residente en Santiago. Email: ndzuniga77@gmail.com 
por su parte, está siempre suscitado por algún objeto o lugar particulares que le hacen evocar alguna vivencia especialmente decisiva. Es lo que ocurre por ejemplo en Dirección única y sobre todo en Infancia en Berlín hacia 1900, donde evoca los recuerdos de su niñez, configurando una ciudad que se construye no solo de la remembranza, sino también del esbozo, de una especie de paisaje hablado, elaborado por ausencia del referente, con lo que recuerdo y escritura se acercan hasta confundir sus contornos.

El recuerdo entonces puede concebirse como una "escritura"; marcas o hendiduras grabadas en la memoria, pero también sobre la superficie del cuerpo: cicatrices, posturas corporales, gestos y modos de hablar, son vestigios de nuestra propia historia. Vestigios que, al modo de la magdalena de Proust, evocan los acontecimientos que hicieron posible su plasmación: "Los héroes, cuyas hazañas dormitaban allí, en la galería, me parecían para mis adentros tan depravados como la multitud de aquellos que gemían azotados por huracanes, empalados en troncos sangrantes, congelados en bloques de hielo del oscuro cráter" (BENJAMIN, 1982, 24). En este fragmento de "Columna Triunfal", podemos apreciar que la sensación de temor está íntimamente ligada a un espacio urbano monumental. En el recuerdo se entrelazan el temor, la Columna y la evocación de las ilustraciones de Doré para el Infierno de Dante. Por supuesto, Benjamin reconstruye esa experiencia, lo que le permite poner en relación, en un texto, los elementos mencionados. Uno de los aspectos más interesantes de esta reconstrucción es la ligazón entre la arquitectura y las sensaciones profundas que esta puede producir. Benjamin explicita que la Columna Triunfal conmemora la victoria en la batalla de Sedán, cuyo aniversario las personas celebraban con visitas a lo alto de la torre. Este gesto de los ciudadanos de sumarse a la celebración parece implicar para Benjamin una forma de plegarse al relato de un poder lo suficientemente efectivo como para marcar la ciudad con un hito de esta naturaleza. En este aspecto, en "Columna Triunfal" es posible apreciar la concurrencia de los principios de orden y simbolismo, que Delfante identifica como los elementos fundamentales que el poder, ya sea político, 
religioso o militar busca instalar en el espacio público: "Estos dos principios generan una voluntad de puesta en escena indispensable para la mediatización inmediata y portadora de la gloria anunciada" (DELFANTE, 2006, 12). Sin embargo, al decir de Benjamin, los ciudadanos de Berlín parecen percibir la Columna Triunfal como un elemento totalmente integrado al paisaje urbano. ¿No es acaso el niño Walter Benjamin el único que parece percibir el verdadero efecto detrás de la Columna Triunfal, cuya majestuosidad se yergue sobre una base que evoca los horrores del infierno?

Algo más enigmática es la referencia al Tiergarten en el apartado del mismo nombre. En la evocación de este parque berlinés, Benjamin menciona las imágenes de las estatuas de los soberanos Federico Guillermo y la reina Luisa, aunque según él mismo señala, se siente más atraído por las figuras que decoran los pedestales. La evocación del Tiergarten está marcada por la realización de una analogía del espacio urbano con la naturaleza no domesticada: "Importa poco no saber orientarse en una ciudad. Perderse, en cambio, en una ciudad como quien se pierde en el bosque, requiere aprendizaje. Los rótulos de las calles deben entonces hablar al que va errando como el crujir de las ramas secas, y las callejuelas de los barrios céntricos reflejarle las horas del día tan claramente como las hondonadas del monte" (BENJAMIN, 1982, 15). La ciudad aparece aquí como un espacio salvaje, plagado de ruidos y señales que el habitante debe saber interpretar, del mismo modo que un aventurero lee las señales del campo o la montaña. La ciudad, el escenario que el ser humano se ha dado para protegerse de las inclemencias de la naturaleza, se ve transformado en este recuerdo por la irrupción de lo desconocido. Paradójicamente, Benjamin señala que perderse en la ciudad "requiere aprendizaje". En este sentido, los aspectos desconocidos que puede presentar la ciudad se ven incorporados a la experiencia de sus habitantes por medio de una práctica aparentemente inocente, pero que para Benjamin se instala en el ámbito del conocimiento. Al decir que perderse en la ciudad requiere aprendizaje, ¿No está aludiendo Benjamin a la necesidad de desautomatizar las rutinas de los habitantes 
de una urbe? De cierto modo, el autor llama la atención sobre la oposición conocido/desconocido que se da en toda ciudad, y donde quizás la única forma de conocer realmente dicha ciudad sea perderse en ella, abandonar las rutas habituales y dejarse asombrar por los nuevos lugares.

Esta idea aparece también en Dirección única, en el apartado "Armas y municiones", donde señala: "Había llegado a Riga para visitar a una amiga. Su casa, la ciudad, el idioma me eran desconocidos. Nadie me esperaba, nadie me conocía. Deambulé dos horas solo por las calles. Nunca he vuelto a verla así" (BENJAMIN, 2005, 28-9). La mirada del desconocido que observa asombrado lo nuevo es de cierto modo análoga a la del filósofo o la del poeta, cuyos oficios dependen en gran medida de la capacidad de asombrarse ante lo nuevo y desconocido, pero también ante lo conocido que se mira como si fuera la primera vez.

Por otra parte, si la ciudad moderna es en gran medida un espacio planificado donde la circulación de los individuos está determinada por dicha planificación, podemos vincular la voluntad benjamineana de perderse en la ciudad con un intento de subversión de esos espacios. Según Richard Sennett, la planificación urbana del siglo XIX apuntó a crear espacios que beneficiaran el desplazamiento individual, al tiempo que dificultaban la movilidad de los grupos organizados (SENNETT, 1997, 344). En una especie particular de flanerie, Benjamin se apropia de la movilidad individual, pero no con el objetivo de obedecer las leyes del desplazamiento urbano moderno, sino de desencajar la compacta coherencia de lo conocido.

El acto de perderse para conocer se reitera una vez más en Dirección única, en la primera parte de "Oficina de objetos perdidos": "No bien empezamos a orientarnos, el paisaje ${ }^{1}$ desaparece de golpe como la fachada de una casa cuando

1 Agradzco al Doctor @ Fracisco Vega su valiosa orientación en el uso del termino alemán Landschaft por parte de Benjamin y sus posibles implicaciones en el ensayo citado.

Doctor ( ) en Literatura con mención en literatura chilena e hispanoamericana por la Universidad de Chile. Chileno, residente en Santiago. Email: ndzuniga77@gmail.com 
entramos en ella. Aún no ha conseguido imponerse gracias a la exploración constante, convertida en costumbre. Una vez que empezamos a orientarnos en algún lugar, aquella imagen primera no podrá reproducirse nunca más" (BENJAMIN, 2005, 37). Alude Benjamin aquí a la acción adormecedora de la costumbre, que oculta a nuestra vista los objetos y lugares más cotidianos. Sin embargo, en esta especie de agotamiento del significado que produce la costumbre puede esconderse también la posibilidad de rasgar ese velo y vislumbrar las cosas desde una nueva perspectiva. Tal como señala Benjamin en "El mercado de la plaza de Magdeburgo", la repetición de un acto puede efectivamente llevar a una contemplación diferente, una verdadera iluminación profana: "por la costumbre de pasearme por ese mercado, se desgastaron las imágenes que presentaba, de modo que ninguna se prestaba al primitivo concepto de la compra y de la venta" (BENJAMIN, 1982, 47). Lo relevante es que, luego del desgaste de las imágenes por su reiteración, el observador se libera de esa primera capa de significado y accede a un mundo donde la compra y venta de productos deja lugar a los colores, olores, sonidos, texturas y toda clase de percepciones de carácter estético. La vertiginosa embriaguez del mercado aparece de pronto como una naturaleza que palpita bajo la superficie de la mera transacción comercial, de donde emergen

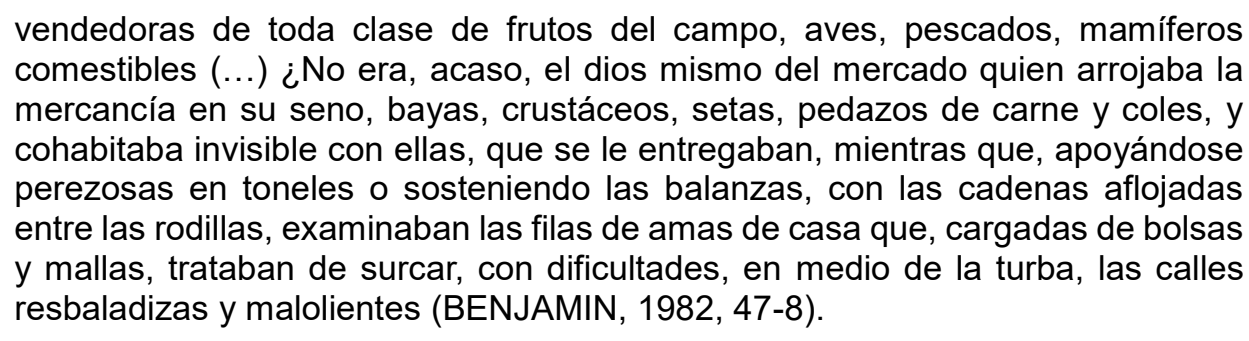

En esta vívida imagen, Benjamin reelabora el caos, la multiplicidad de estímulos fragmentarios y diversos que puede ofrecer un mercado público y lo presenta casi en términos armónicos. Lo interesante de su reconstrucción es que propone esta imagen como efecto de un desgaste inicial producido por la costumbre; de la diversidad y heterogeneidad de los estímulos del mercado, Benjamin extrae no solo una imagen, sino un sentido de lectura de esa imagen. Es 
decir, es en este tipo de construcciones donde se puede apreciar el método benjamineano de búsqueda y elaboración de un sentido a partir de elementos fragmentarios.

Si observáramos estos fragmentos de texto como piezas de cerámica recuperadas por un arqueólogo y dispuestas sobre una superficie, podríamos decir que sin lugar a dudas el motivo de base es el mismo, por más que se presente con algunas variaciones. Ese motivo es el acto de perderse en la ciudad como una forma de conocerla. De este modo, el laberinto urbano solo podrá ser recorrido y quizás desentrañado por aquél que se deja extraviar por la ciudad, aquél que se deja invadir por ella y se sumerge en sus calles y rincones, redescubriendo su lenguaje una y otra vez. Esta misma sensación de embriaguez reaparecerá en la lectura que Benjamin hace de Baudelaire, aunque no en un lugar tan preponderante como en los textos citados aquí.

Hasta el momento hemos expuesto algunos de los planteamientos que Walter Benjamin dedica fundamentalmente a Berlín. Sin embargo, la ciudad que concita más vivamente el interés del filósofo y la que mayor presencia tiene en su trabajo crítico es París. Ya sea que indaguemos en El París del Segundo Imperio en Baudelaire, Algunos motivos sobre Baudelaire, Zentralpark o El libro de los pasajes, la imagen -o más precisamente, las imágenes- que Benjamin elabora de la capital francesa resultan siempre diversas, fascinantes y contradictorias. Del mismo modo, los personajes que concitan su atención reflejan igualmente la diversidad, fascinación y contradicciones de la ciudad que habitan.

Fiel a su búsqueda del lado menos rutilante de la urbe, Benjamin pone su atención en espacios y sujetos marginales, los que confluyen a la luz de agitadas circunstancias y terminan por crear una serie de instantáneas que, al modo de las fotografías de Atget, exhiben los aspectos residuales del capitalismo industrial del siglo XIX. Con residuales nos referimos a los efectos no explícitamente buscados 
por el sistema capitalista y la producción industrial pero que, sin embargo, pueden repercutir en las lógicas culturales que estos generan.

En "La bohemia" -primera parte de El París del Segundo Imperio en Baudelaire-, Benjamin identifica a los sujetos que integran este grupo o que circulan en torno a él y los lugares que habitan: las tabernas de los vinateros, las barricadas y las calles. En este sentido, es posible advertir en Benjamin la elaboración de una especie de "ciudad bohemia", donde los dos primeros espacios corresponden a los conspiradores (tanto los profesionales como los de ocasión), en tanto que la calle corresponde a los traperos, lugar donde ejercen su actividad de recolección de desechos.

Para su análisis del fenómeno de la bohemia, Benjamin recurre a los escritos de Marx y Les fleurs du mal de Baudelaire. Este cruce textual da como resultado una serie de fragmentos disímiles en tono e intenciones, pero dispuestos de tal modo que de sus mismas contradicciones emergen las polaridades que tensionan el París del siglo XIX. Benjamin describe a la bohemia como "la masa indeterminada, desmembrada, traída y llevada de aquí para allá" (MARX cit. en BENJAMIN, 2012a, 24) cuyo objetivo al conjurar no es otro que "derribar al gobierno existente, despreciando en lo más hondo la ilustración teórica de los trabajadores acerca de sus intereses de clase" (MARX y ENGELS cit. en BENJAMIN, 2012a, 25) en gran medida para situar a Baudelaire en relación con este grupo. Sin embargo, las cambiantes posturas políticas del poeta parecen desconcertar a Benjamin, quien expone estas contradicciones, aunque no por esto su juicio deja de ser tajante: "Los atisbos políticos de Baudelaire no sobrepasan en el fondo los de estos conspiradores profesionales" (BENJAMIN, 2012a 25). Para Benjamin, la conducta errática de Baudelaire parece convertirse en un síntoma de su tiempo. Si sus posturas políticas son cambiantes, en ello puede observarse no solo una subjetividad que duda de su entorno, sino justamente un contexto que se ha ensanchado lo suficiente como para que se manifieste la contradicción. Esta forma de leer la relación entre Baudelaire y el París del XIX que Benjamin expone, nos 
permite esbozar su posible concepto de ciudad moderna, cual es la subjetivización del espacio urbano. Es decir, no se trata ya de que el poeta proyecte ciertos estados de ánimo sobre el paisaje de la ciudad, o que personifique objetos con su voz, sino que la materialidad misma de la urbe ingresa en el texto a través de la mirada del poeta. En otras palabras, no se trataría de un sujeto que toma distancia y habla de su objeto, sino que ambos están tan inextricablemente vinculados que sería difícil decir si se trata de Baudelaire escribiendo sobre París o si es la propia ciudad -en tanto contexto histórico material inmediato- la que surge a través de los poemas de Baudelaire. En Le Cygne podemos apreciar la compleja relación del poeta con su ciudad:

¡Cambia París! ¡Mas nada en mi melancolía

se ha movido! Suburbios nuevos, viejos palacios, bloques, andamios, todo se me vuelve alegórico, y pesan más que rocas mis recuerdos queridos (BAUDELAIRE, 2015, 343).

En estos versos podemos apreciar que Baudelaire parece resentir los cambios realizados en la superficie de la ciudad casi de un modo corporal. La ciudad es objeto de la vorágine moderna, y la voz poética dice que todo se le vuelve alegórico, aunque no se explicita en qué consiste esa alegoría, o cuáles serían los términos representados. Sin embargo, es posible relacionar tanto la melancolía como los recuerdos a esa vorágine que se apodera de la ciudad. La voz del poema da cuenta de una cierta inestabilidad, al mismo tiempo que se vincula directamente con el espacio urbano. Hemos dicho que para Benjamin un posible concepto de ciudad moderna tenga relación con la subjetivización del espacio urbano. A partir de la lectura de Baudelaire, podemos aventurar que quizá también se trate de una espacialización urbana del cuerpo. Si, tal como plantea Richard Sennett en Carne y piedra, desde el descubrimiento de la circulación de la sangre por William Harvey en el siglo XVII y la influencia de este descubrimiento en La riqueza de las naciones 
de Adam Smith (1776), las nociones de circulación y de respiración fueron extrapoladas del cuerpo a la planificación urbana (SENNETT, 1997, 273 y ss.), es posible pensar que este desplazamiento puso en relación las ideas de cuerpo y ciudad, con lo que los individuos modernos ya no serían solo habitantes de una urbe, sino que formarían parte indisoluble de su tejido. De este modo, tanto la alegoría de Baudelaire como la lectura que Benjamin hace de París pueden comprenderse desde la relación sujeto-ciudad.

En un sentido similar se refiere Benjamin a la figura del trapero. Marginal entre los marginales, "el trapero fascinó a su época" (BENJAMIN, 2012a, 31), y aunque el autor no lo sitúa directamente como parte de la bohemia, dice que "todos los que formaban parte de esta, desde el literato hasta el conspirador profesional, podían reencontrar en el trapero algo de sí mismos" (BENJAMIN, 2012, 32). En el trapero encontramos los efectos más descarnados del capitalismo industrial. No solo por la pauperización absoluta de los individuos, sino porque incluso esta precariedad se vuelve funcional al sistema privado de producción. Dicho de otro modo, el trapero es una especie de subproducto, la contracara de lo que ante otras clases sociales aparecía como "lujo industrial" (BENJAMIN, 2012b, 865).

El trapero, en su recorrido por las calles de la ciudad, recoge los residuos de la producción: "Los traperos aparecieron en mayor número en las ciudades desde que los nuevos procedimientos industriales dieron a los desperdicios un cierto valor" (BENJAMIN, 2012a, 31). Para Benjamin, el trapero muestra el rostro deshumanizador de la modernidad, pero también su proceder revela ciertos paralelos con el poeta. Si el trapero recorre las calles recolectando desperdicios, Baudelaire no lo hace menos, ya que es también un recolector de imágenes de la modernidad, tal como lo muestran, por ejemplo, lo poemas de la sección "Cuadros parisinos", de Las flores del mal.

Los habitantes de esta especie de ciudad bohemia circulan no solo por los márgenes de la ciudad, sino también en sus intersticios. Conspiradores y traperos 
son en cierto modo una amenaza para el orden que dimana del poder que intenta dominar la ciudad. Si París, como plantea Benjamin "tiene pasión por las perspectivas especulares" (BENJAMIN, 2012b, 869) y si sus hitos monumentales como "El Arco del Triunfo, el Sacré Coeur, incluso el Panteón aparecen de lejos como imágenes suspendidas a media altura, entreabriendo arquitectónicamente el espejismo" (Ibíd.), es decir, si el relato del poder juega en París a la multiplicación de su propia presencia, entonces la ciudad de los bohemios y traperos cuestiona ese orden, o bien pone en evidencia su inestabilidad y le devuelve su propia imagen, no sin antes invertir el espejismo: la abundancia se refleja en la miseria, el poder, en la subversión.

La ciudad de bohemios y traperos aparece entonces como una contra-ciudad que, al modo de una cuña, dificultara el giro de una rueda. La fricción producida entre la cuña y la rueda, entre la ciudad y la contra-ciudad, es el fenómeno que interesa a Benjamin, ya que la fricción de ambos espacios palpita no solo en las arterias de la urbe, sino en la propia subjetividad de los individuos. Tal como Benjamin señala en Zentralpark: "Lo que resuena en Baudelaire, cuando conjura París en sus versos, es la caducidad y fragilidad de esta gran ciudad" (BENJAMIN, 2012a, 265). Esta observación de Benjamin puede relacionarse directamente con los versos antes citados de Le Cygne, donde Baudelaire expresa el carácter cambiante de París, ya que su cambio constante estaría revelando cierta impermanencia que el poeta parece predecir y que Benjamin lee en términos de caducidad y fragilidad.

En la segunda parte de El París del Segundo Imperio en Baudelaire hace su aparición el que probablemente sea el más reconocido de los personajes parisinos que atraen la atención de Benjamin. Se trata, evidentemente, del flâneur. Figura contradictoria, que en todo momento evoca el individualismo moderno del que habla Sennett en Carne y piedra, el flâneur debe su existencia y su quehacer a las condiciones del capitalismo industrial que incidieron en la creación de los pasajes. Difícilmente el flâneur habría podido surgir dentro de una configuración urbana 
diferente. Según la Guía ilustrada de París de 1852 que cita Benjamin, un pasaje "es una ciudad e incluso un mundo en pequeño, en el que el comprador ávido encontrará todo lo que necesita" (BENJAMIN, 2012b, 865). Es en este reducido mundo de exhibición y consumo donde el flâneur tiene su hábitat "natural": El bulevar es la vivienda del 'flâneur', que está como en su casa entre fachadas, igual que el burgués en sus cuatro paredes" (BENJAMIN, 2012a, 51). Atrapado por las deslumbrantes novedades que ofrecen los pasajes, el flâneur aparece determinado por este laberinto urbano. Si por una parte su conducta afirma el individualismo capitalista, por otra, su iniciativa individual se ve constreñida a deambular entre las estrechas galerías, dejando que su vista salte de vitrina en vitrina. Sin otra ocupación que su propio deleite, el flâneur se deja atrapar por la diversidad de estímulos que ofrecen los pasajes: medias, peines, bastones y paraguas, también libros, enciclopedias y botones.

El espacio del pasaje escenifica el espectáculo capitalista por excelencia, esto es, la idea de su propia perennidad. La ordenada multiplicidad del pasaje, que es según Benjamin "una cosa intermedia entre la calle y el interior" (Ibíd.), provee al flâneur una ilusión de cosmopolitismo y abundancia que no se replica ni se refrenda fuera de él. Es un mundo que se cierra sobre sí mismo. Y, al igual que sucede con las perspectivas monumentales de París, el pasaje se presenta como un mundo especular:

El aspecto puramente externo y secundario de la ambigüedad de los pasajes lo proporciona su abundancia de espejos, que amplían el espacio como en un cuento de hadas, dificultando la orientación (...) aunque este mundo de espejos pueda tener varios e incluso infinitos significados, sigue siendo ambiguo, en el sentido de un mundo especular. Parpadea; es siempre este uno y jamás nada, de donde sale enseguida otro. El espacio, que se transforma, lo hace en el seno de la nada (BENJAMIN, 2012b, 869-70). 
La falsa perspectiva que provee el pasaje responde a una planificación que intenta crear la ilusión de multiplicidad. Aunque no es el objetivo de este ensayo, es probable que este aspecto especular de los pasajes parisinos tenga alguna relación con el concepto benjamineano de fantasmagoría, en la medida en que ocurre un ocultamiento de la verdadera naturaleza de la mercancía, en tanto no se trata tan solo de los objetos expuestos en las tiendas, sino de las tiendas y hasta del pasaje mismo, en su calidad de puesta en escena de una realidad que no puede verificarse sino al interior del pasaje mismo.

La disposición especular del pasaje tiene por finalidad despertar la avidez por lo nuevo. Sin embargo, la novedad será siempre aparente. No se trata aquí de realizar un redescubrimiento, como planteamos al inicio de este ensayo, sino que lo que el pasaje propone es que los objetos en exhibición, tanto como los lugares donde se exhiben, aparecen permanentemente renovados, de ahí el uso de las perspectivas especulares para distorsionar el espacio. Se trata entonces de un encubrimiento permanente de la caducidad y la fragilidad como características propias del espacio urbano de la modernidad industrial.

\section{Perspectivas}

Resulta, por decir lo menos, algo contradictorio plantearse la posibilidad de presentar conclusiones respecto de una obra como la de Walter Benjamin. Su trabajo no solo es voluminoso, sino además, variado y hasta enigmático, por lo que ser concluyente puede resultar incluso pretencioso. Por otra parte, si algo caracteriza a Benjamin es la utilización de un método casi perifrástico, tentativo, donde rondar el objeto es más relevante que agotarlo. Por ello pensamos que, si algo de conclusivo tiene esta última parte de nuestro ensayo, serán conclusiones a todo evento aproximativas y provisorias. Hecha esta salvedad, abordaremos algunos de los elementos que están presentes en el concepto de ciudad moderna de Walter Benjamin. 
La primera ciudad benjamineana que abordamos fue Berlín. Esta aparece bosquejada a la luz del recuerdo de infancia, por lo que los espacios y vivencias están visiblemente idealizados por la distancia y la imaginación poética del autor. Sin embargo, el texto mismo parece surgir de un ejercicio de boceteo, un trazar el recuerdo a mano alzada antes de que este se desvanezca como un sueño. Berlín aparece entonces bosquejada, reimaginada y recobrada del sueño de la infancia. Sería por tanto imposible que apareciera objetiva y completa. Por el contrario, su evocación la subjetiviza y al escribirla, la vuelve texto. Se trata de una ciudad textual, solo existente (y persistente) en el escrito benjamineano que la toma al mismo tiempo como punto de partida y como meta.

Tanto en Infancia en Berlín hacia 1900 como en Dirección única, la aproximación a la ciudad moderna se realiza por medio de la yuxtaposición y acumulación de fragmentos. Ninguno de ellos está situado en posición central o distribuidora de sentidos de lectura. Por el contrario, los fragmentos pueden evocarse y referenciarse unos a otros con total movilidad. Pensamos que esta fragmentariedad, tanto del recuerdo como del texto, propone tácitamente una forma de pensar la ciudad, más allá de los ejes temáticos que se puedan vincular con ella. Sin perjuicio de esto, la remembranza de Berlín aporta elementos como el temor, pero también la seguridad de la casa burguesa y la protección de la familia. En ese sentido, por tratarse de evocaciones de una infancia sin grandes sobresaltos, la ciudad aparece como un espacio mayoritariamente tranquilo, aunque siempre parece ocultar algún secreto detrás de sus fachadas. A pesar de su calma casi rural, la pulsión sexual, lo mismo que la pobreza y la violencia del crimen amenazan a la ciudad en el recuerdo de Benjamin.

En gran medida contrapuesta a Berlín aparece la ciudad de París. Recobrada principalmente a partir de los textos en verso y en prosa de Charles Baudelaire, el París de Benjamin aparece caótico y vertiginoso. Una ciudad cuyos estímulos serían muy difíciles de procesar. De ahí que la fragmentariedad con la que Benjamin aborda el fenómeno París se radicaliza al nivel que le conocemos en 
El libro de los pasajes, donde al método de la recolección y del archivo se agregan las variaciones sobre el tema que, como indicamos al inicio de esta sección, intentan rondarlo y acercarse, mas nunca agotarlo por completo.

En una dirección opuesta al pensamiento de los planificadores y teóricos urbanos, Benjamin cuestiona los conceptos de coherencia y cohesión, al menos tomados de modo apriorístico. Su interés por el fragmento y su método igualmente fragmentario, dejan estos conceptos en duda a la hora de hablar de la ciudad moderna. Por el contrario, la idea benjamineana de ciudad aparece al invertir el signo de estos conceptos, o más bien al volverlos activos, conjugados por un sujeto cuyas prácticas los subvierten: deambular a contrapelo de las disposiciones y escenificaciones urbanas del poder permitiría re-crear, re-elaborar y re-descubrir un sentido que ha sido disgregado por la acumulación de fragmentos aparentemente discordantes. Tal como propone el autor en Zentralpark, a propósito de la imagen del caleidoscopio como metáfora de una historia creada por las clases hegemónicas: "Los conceptos de los dominantes han sido siempre el espejo gracias al que surgió la imagen de un 'orden'. Hay que romper el caleidoscopio" (BENJAMIN, 2012a, 249). El método benjamineano en torno a la ciudad se propone en la recolección de fragmentos, cuyo estudio en relación unos con otros puede revelar oposiciones y complementariedades, de donde se pueden inferir los sentidos posibles.

Es en la búsqueda de las huellas dejadas en la ciudad por las fuerzas que sobre ella actúan donde Benjamin observa el dilema del sujeto moderno, cuyo entorno material y cultural ha disgregado el sentido. La ciudad aparece ante sus ojos como los fragmentos de un mapa rasgado. Sin embargo, el mapa ya no puede ser reconstituido. Solo quedaría actuar como un arqueólogo, al desenterrar los fragmentos del sentido dispersado, por una parte, y como detective, al elaborar inferencias válidas a partir de las huellas y pistas encontradas. La ciudad moderna aparece para Benjamin como el escenario de la disgregación del sentido, pero también como la posibilidad de rastrear, por medio de una arqueología tanto del 
pasado como del presente, los fragmentos que nos permitan su lectura y reelaboración constantes.

Doctor (c) en Literatura con mención en literatura chilena e hispanoamericana por la Universidad de Chile. Chileno, residente en Santiago. Email: ndzuniga77@gmail.com 


\section{REFERÊNCIAS}

BAUDELAIRE, C. Las flores del mal. (Madrid: Cátedra, 2015).

BENJAMIN, W. Dirección única. (Madrid: Alfaguara, 2005).

BENJAMIN, W. El París de Baudelaire. (Buenos Aires: Eterna Cadencia, 2012a).

BENJAMIN, W. lluminaciones II. Baudelaire, un poeta en el esplendor del capitalismo (Madrid: Taurus, 1972).

BENJAMIN, W. Infancia en Berlín hacia 1900 (Madrid: Alfaguara, 1982).

BENJAMIN, W. Obras. Libro I, vol 2. (Madrid: Abada, 2012b).

DELFANTE, C. Gran historia de la ciudad: de Mesopotamia a Estados Unidos. (Madrid: Abada, 2006).

MUNIZAGA, G. Las ciudades y su historia: una aproximación. (Santiago:

Pontificia Universidad Católica de Chile, 1997)

SENNETT, R. Carne y piedra. El cuerpo y la ciudad en la civilización occidental. (Madrid: Alianza, 1997).

WILLIAMS, R. Marxismo y literatura. (Barcelona: Península, 2000). 